\title{
Selective Epoxidation of Fatty Acids and Fatty Acid Methyl Esters by Fungal Peroxygenases
}

\author{
Carmen Aranda ${ }^{\ddagger}$, Andrés Olmedo ${ }^{\ddagger}$, Jan Kiebist, Katrin Scheibner, José C. del Río, Angel T. Martínez, \\ and Ana Gutiérrez*
}

\begin{abstract}
Recently discovered fungal unspecific peroxygenases from Marasmius rotula and Chaetomium globosum catalyze the epoxidation of unsaturated fatty acids (FA) and FA methyl esters (FAME), unlike the well-known peroxygenases from Agrocybe aegerita and Coprinopsis cinerea. Reactions of a series of unsaturated FA and FAME with cis-configuration revealed high (up to $100 \%)$ substrate conversion and selectivity towards epoxidation, although some significant differences were observed between enzymes and substrates with the best results being obtained with the C. globosum enzyme. This and the M. rotula peroxygenase appear as promising biocatalysts for the environmentally-friendly production of reactive FA epoxides given their self-sufficient monooxygenase activity and the high conversion rate and epoxidation selectivity.
\end{abstract}

Oils and fats are among the most important renewable feedstock of the chemical industry, whose possibilities are still far from being fully exploited. ${ }^{[1]}$ By simple industrial operations, fatty acids (FA) are available from vegetable oils in such purity that they may be used for further chemical transformations. Their conversion to FA methyl esters (FAME) is a well-known application of fats and oils, largely investigated for biodiesel production. Moreover, unsaturated FA and FAME can be further epoxidized, and used in industrial syntheses of chemicals and intermediates.

The industrial-scale epoxidation of unsaturated FA compounds is generally carried out by the Prileshajev ${ }^{[2]}$ reaction via percarboxylic acids (Scheme $1 \mathrm{a}_{2}$ ). However, this method, which often includes strong mineral acids as catalysts for the "in situ" generation of peracids (Scheme 1 $a_{1}$ ), suffers from several drawbacks such as the relatively low selectivity for epoxides due to oxirane ring opening in the acidic medium, the corrosive nature of acids, and the unstable character of peracids. ${ }^{[3]}$ Many studies have been aimed at searching an alternative, such as the chemoenzymatic synthesis with lipases catalyzing the carboxylic acid reaction with hydrogen peroxide. ${ }^{[4 ; 5]}$ However, the latter reaction maintains most drawbacks of peracid-based epoxidation. Therefore, direct enzymatic processes emerge as an alternative solution for more selective and environmentally friendly epoxidation of unsaturated lipids. Several enzymes are

\footnotetext{
[^] C. Aranda, A. Olmedo, Prof. J. C. del Río, Prof. A. Gutiérrez Instituto de Recursos Naturales y Agrobiología de Sevilla, CSIC Reina Mercedes 10, E-41012 Seville (Spain)

E-mail: anagu@irnase.csic.es

J. Kiebist, Prof. K. Scheibner

JenaBios $\mathrm{GmbH}$

Orlaweg 2, D-00743 Jena (Germany)
}

Prof. A. T. Martínez

Centro de Investigaciones Biológicas, CSIC

Ramiro de Maeztu 9, E-28040 Madrid (Spain)

[ $\ddagger$ ] These authors contributed equally to the work

\section{Conventional chemical route}

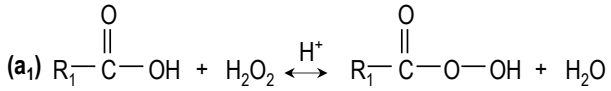

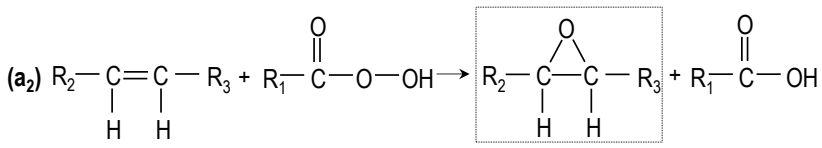

This work: new enzymatic route

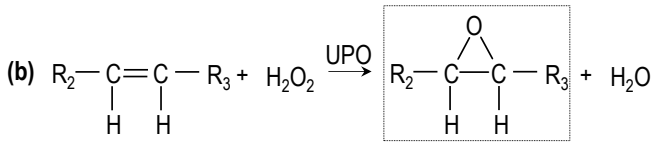

Scheme 1. Chemical and enzymatic routes for the epoxidation of fatty acids.

known to catalyze epoxidation directly, such as cytochrome P450 monooxygenases (P450), diiron-center oxygenases, and plant peroxygenases. ${ }^{[5 ; 6]}$ However, they present some drawbacks, such as their intracellular nature, and the requirement for costly cosubstrates in the two former cases.

Here, we show a promising enzymatic technology to epoxidize unsaturated FA (Scheme 1b) under mild and environmentally-friendly conditions, as potential alternative to the above chemical and enzymatic epoxidations. This includes the use of two recently discovered unspecific peroxygenases (UPO, EC 1.11.2.1), from the fungi Marasmius rotula (MroUPO) ${ }^{[7]}$ and Chaetomium globosum (Cg/UPO). ${ }^{[8]}$ These and related fungal peroxygenases represent a new class of enzymes that eludes some of the limitations of other monooxygenases since they are secreted proteins, therefore far more stable, and only require $\mathrm{H}_{2} \mathrm{O}_{2}$ for activation.

Peroxygenases are structurally related to the P450s, as they also contain the heme prosthetic group coordinated by a cysteine ligand, but they do not depend on the reductive activation of molecular oxygen and catalyze the transfer of an oxygen atom from peroxide to substrates. ${ }^{[9]}$ Initially, these UPO were shown to catalyze oxygenation reactions on aromatic compounds, ${ }^{[10]}$ and their action on aliphatic compounds was demonstrated later. ${ }^{[11]}$ After the first UPO discovered in Agrocybe aegerita (AaeUPO), ${ }^{[12]}$ similar enzymes were found in other basidiomycetes, such as $M$. rotula, and there are indications for their widespread occurrence in the fungal kingdom. ${ }^{[13]}$ Over one-hundred peroxygenase-type genes have been identified in the analysis of 24 basidiomycete genomes, ${ }^{[14]}$ including Coprinopsis cinerea. ${ }^{[15]}$ One UPO from the latter fungus is produced as a recombinant protein ( $\mathrm{r}$ CciUPO) by Novozymes (Bagsvaerd, Denmark) (Figure S1A). ${ }^{[16]}$ Interestingly, the recently described MroUPO presents differences with the best studied fungal peroxygenases, such as the ability of oxidizing bulkier substrates, ${ }^{[9 ; 17]}$ the terminal hydroxylation of $n$-alkanes ${ }^{[18]}$ and the chain-shortening of carboxylic acids. ${ }^{[19]}$ On the other hand, 
Cg/UPO is the fourth wild-type described UPO, and the first isolated from an ascomycete. ${ }^{[8]}$

The reactions of purified MroUPO and Cg/UPO (Figure $\mathrm{S} 1 \mathrm{~B}, \mathrm{C}$ ) with a series of cis-monounsaturated FA (from C14:1 to C22:1), showed that both enzymes are capable of oxygenating these substrates, Cg/UPO being more active since it achieved maximal substrate conversion with lower enzyme doses (Table 1). Interestingly, both peroxygenases generated the epoxidized derivatives as main products (Figures $1 \mathrm{~A}-\mathrm{B}$ ), unlike the other wellknown AaeUPO (not shown) and rCciUPO that were not able to epoxidize the double bond and instead, produced the hydroxyderivatives at the subterminal positions (Figure 1C). Therefore, whereas AaeUPO and rCciUPO shows similar regioselectivity towards saturated and unsaturated FA, MroUPO and CgNPO behave differently, hydroxylating at the terminal and/or subterminal positions the saturated FA and oxygenating the double bonds of unsaturated ones. The hydroxylation of FA at the subterminal positions by AaeUPO and $\mathrm{rCciUPO}$ was previously described. ${ }^{[11 ; 16]}$ However, the epoxidation of a fatty acid by a fungal peroxygenase is revealed here for the first time. Moreover, whereas CgNJPO was highly selective with all unsaturated FA, over $90 \%$ epoxidation except with erucic (C22:1) acid, epoxidation by MroUPO depended on FA chain length, showing the highest value with myristoleic (C14:1) acid.

Besides epoxides, minor amounts of other products were found with CgNUPO and especially with MroUPO, such as oxygenated derivatives of epoxidized FA (ED) and hydroxylated

Table 1. Monounsaturated FA $(\mathrm{R}=\mathrm{H})$ and FAME $\left(\mathrm{R}=\mathrm{CH}_{3}\right)$ reactions with $\mathrm{Cg} / \mathrm{UPO}$ and MroUPO doses yielding maximal conversion into epoxides, together with other oxygenated (hydroxyl, keto and carboxyl) derivatives at different positions (arrows)

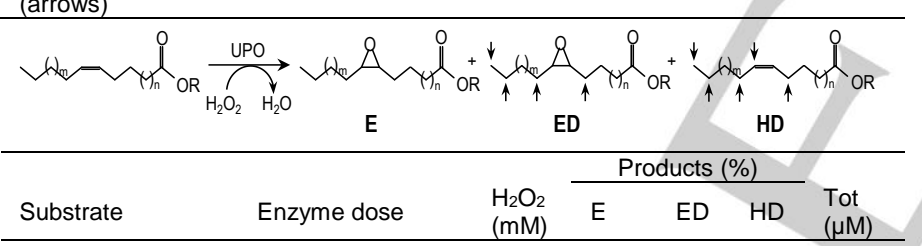

\begin{tabular}{llllllll}
\hline $\mathrm{R}=\mathrm{H}$ & & & & & & \\
$14: 1$ cis- $\Delta 9$ & CgNPO & $60 \mathrm{nM}$ & 5 & 99 & - & 1 & 98 \\
$(\mathrm{n}=5, \mathrm{~m}=1)$ & MroUPO & $200 \mathrm{nM}$ & 5 & 86 & 8 & 6 & 99 \\
$16: 1$ cis- $\Delta 9$ & CgNPO & $60 \mathrm{nM}$ & 5 & 91 & 4 & 5 & 99 \\
$(\mathrm{n}=5, \mathrm{~m}=3)$ & MroUPO & $200 \mathrm{nM}$ & 2.5 & 65 & 17 & 18 & 99 \\
$18: 1$ cis- $\Delta 9$ & CgNPO & $60 \mathrm{nM}$ & 2.5 & 91 & 2 & 7 & 99 \\
$(\mathrm{n}=5, \mathrm{~m}=5)$ & MroUPO & $200 \mathrm{nM}$ & 5 & 38 & 61 & 1 & 96 \\
$20: 1$ cis- $\Delta 11$ & CgNPPO & $60 \mathrm{nM}$ & 5 & 95 & 4 & 1 & 94 \\
$(\mathrm{n}=7, \mathrm{~m}=5)$ & MroUPO & $400 \mathrm{nM}$ & 2.5 & 62 & 7 & 31 & 99 \\
$22: 1$ cis- $\Delta 13$ & CgNPO & $250 \mathrm{nM}$ & 2.5 & 50 & 12 & 39 & $77^{*}$ \\
$(\mathrm{n}=9, \mathrm{~m}=5)$ & MroUPO & $400 \mathrm{nM}$ & 5 & 67 & 10 & 23 & 91 \\
$\mathrm{R}=\mathrm{CH} \mathrm{H}_{3}$ & & & & & & & \\
$14: 1$ cis- $\Delta 9$ & CgNPO & $60 \mathrm{nM}$ & 2.5 & 100 & - & - & 94 \\
& MroUPO & $200 \mathrm{nM}^{c}$ & 2.5 & 68 & 13 & 19 & 100 \\
$18: 1$ cis- $\Delta 9$ & CgNUPO & $1 \mu \mathrm{M}^{b}$ & 5 & 98 & - & 2 & $75^{*}$ \\
& MroUPO & $200 \mathrm{nM}^{c}$ & 2.5 & 73 & 7 & 21 & 93
\end{tabular}

Substrates $(100 \mu \mathrm{M})$, enzyme doses, and estimated total products $(\mu \mathrm{M})$, relative abundance (\% of total products) of epoxide (E), epoxide derivatives (ED), hydroxylated derivatives (HD) are shown. Reactions were performed in $20 \%$ acetone, $30 \mathrm{~min}$ at $30^{\circ} \mathrm{C}$ except for reactions ${ }^{a, b}$ and $c$ that were performed in $40 \%$ acetone at $40^{\circ} \mathrm{C}$, for $30 \mathrm{~min}, 60 \mathrm{~min}$ and $120 \mathrm{~min}$, respectively. ${ }^{*}$ Higher enzyme concentration (up to $500 \mathrm{nM}$ ) did not improve conversion. See Figure S2 for GCMS of authentic standards and Figures S3A,S4 for mass spectra of E and ED.
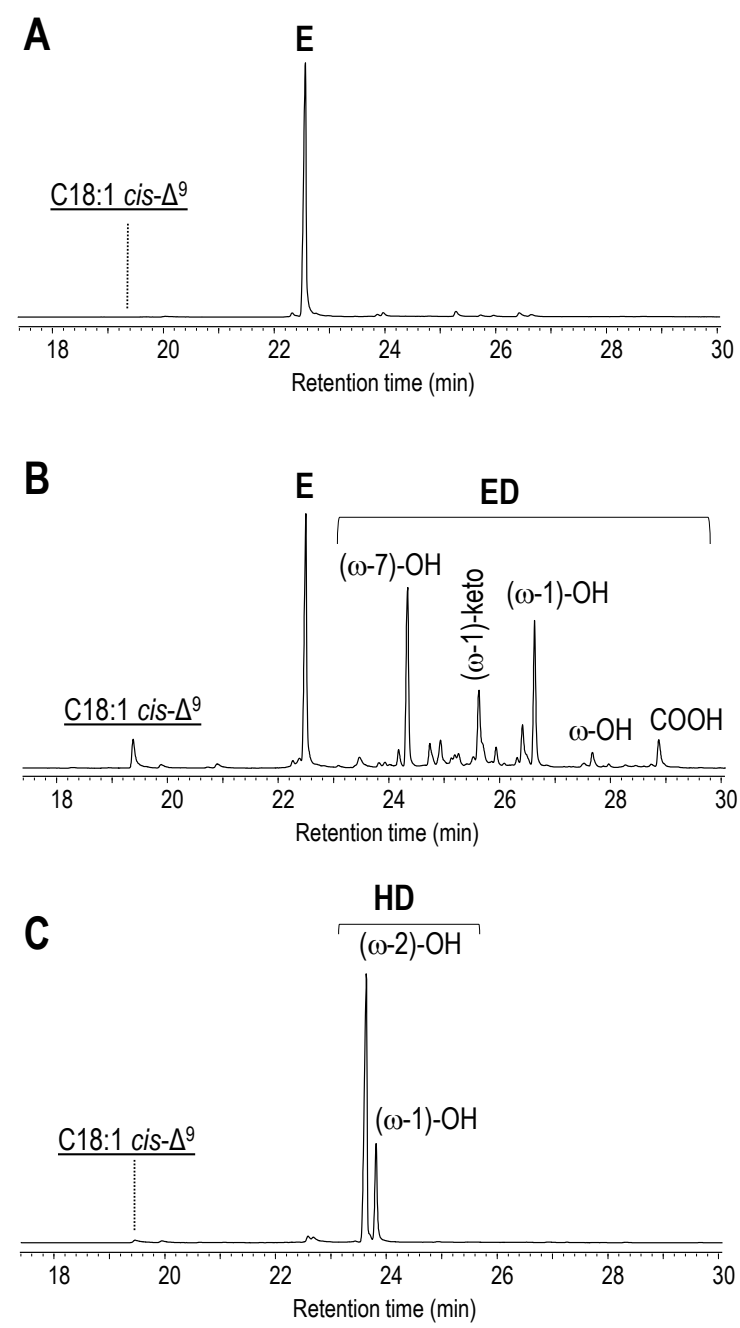

Figure 1. GC-MS of reactions of oleic acid (underlined) at 30 min with $60 \mathrm{nM}$ CgIUPO (A), $200 \mathrm{nM}$ MroUPO (B), and $100 \mathrm{nM}$ rCciUPO (C), showing the epoxide (E), epoxide derivatives (ED) and the hydroxylated derivatives (HD) of oleic acid.

derivatives of FA (HD) mainly at terminal or subterminal and positions of the carbon chain, and at the allylic positions (Table 1, Figure 1B). The higher efficiency and selectivity of $\mathrm{Cg}$ (UPO than MroUPO for epoxidation of most FA is shown in reactions with oleic (C18:1) acid (Figures S5-S6). Curiously, erucic acid, an abundant fatty acid in rapeseed and mustard oils, was transformed and epoxidized at a larger extent by MroUPO. The high selectivity of these UPOs epoxidizing oleic and palmitoleic (C16:1) acids (up to 100\%) differs from that of P450 (BM3) where hydroxylation ( $>97 \%$ and $65 \%$, respectively) predominated over epoxidation (<3\% and 35\%). ${ }^{[6]}$

In addition to monounsaturated FA, some polyunsaturated FA (linoleic and $\alpha$ - and $\gamma$-linolenic acids) abundant in vegetable oils were tested as substrates. Although both UPOs transformed almost completely linoleic acid at the highest enzyme doses (Table 2), Cg/UPO was more selective producing the diepoxide (both syn and anti-enantiomers) in very high yield (92\% of total products) (Figure 2A). MroUPO, besides the epoxides also generated hydroxylated derivatives of the monoepoxides and oxygenated derivatives at allylic positions (mainly at $\omega-7$ ) (Figure 
Table 2. Oxidation of linoleic acid and its methyl ester by CgNPPO and MroUPO

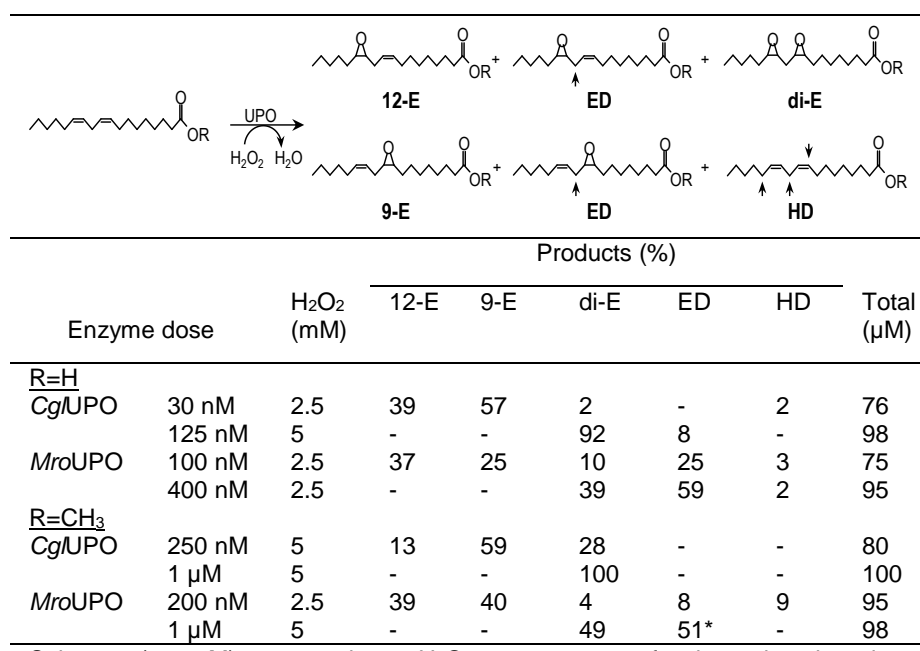

Substrate $(100 \mu \mathrm{M})$, enzyme doses, $\mathrm{H}_{2} \mathrm{O}_{2}$ conc., amount of estimated total products $(\mu \mathrm{M})$ and relative abundance (\% of total products) of 12-epoxide (12-E), 9-epoxide (9-E), di-epoxide (di-E), epoxide derivatives (ED) and hydroxylated derivatives (HD) are shown. Arrows indicate the main chain positions oxidized by the enzymes in epoxidized derivatives (ED) and hydroxylated derivatives (HD). Reactions conditions: $20 \%$ acetone at $30^{\circ} \mathrm{C}, 30 \mathrm{~min}(\mathrm{R}=\mathrm{H}), 40 \%$ acetone at $40^{\circ} \mathrm{C}, 60 \mathrm{~min}$ (CgNPO) and $120 \mathrm{~min}$ (MroUPO) $\left(\mathrm{R}=\mathrm{CH}_{3}\right) .{ }^{*}$ Mono- and di-epoxide derivative. See Figure S7 for GC-MS of authentic standards and Figures S3B, S8 for mass spectra of $E$ and $E D$.

2B). When lower doses of enzymes were used, a predominance of monoepoxides over diepoxides was observed (Table 2).
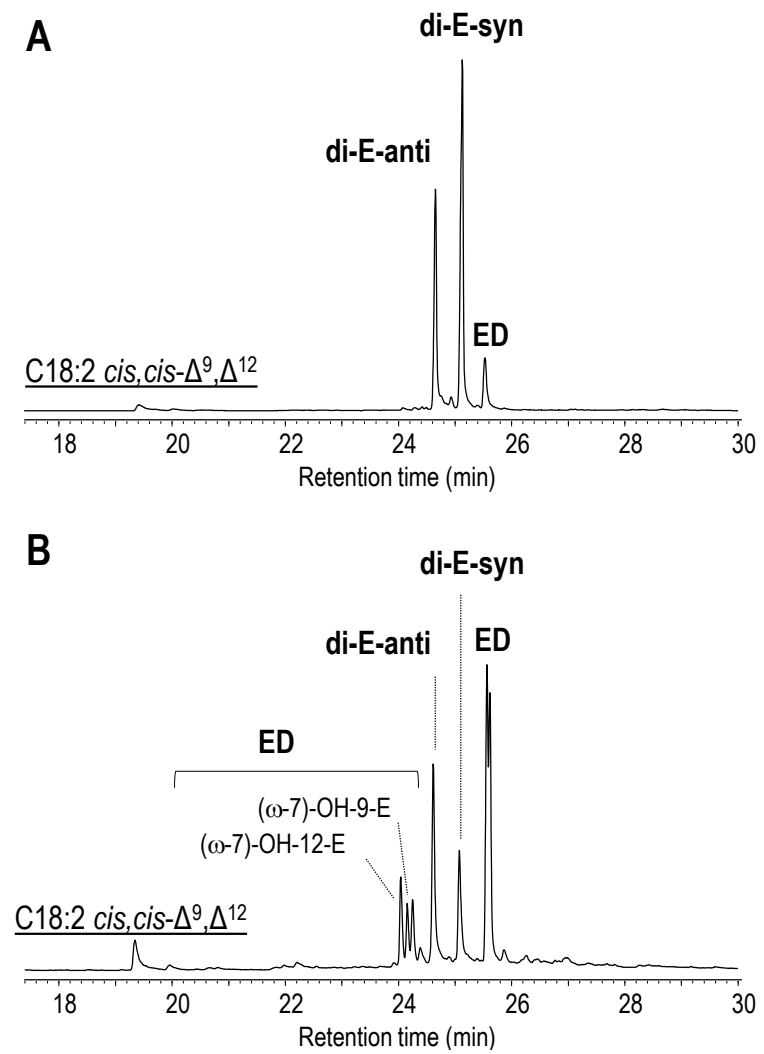

Figure 2. GC-MS of reactions of linoleic acid (underlined) at $30 \mathrm{~min}$ with 125 nM CgNPPO (A) and 400 nM MroUPO (B), showing the diepoxides (di-E), epoxide derivatives (ED) and the hydroxylated derivatives of linoleic acid (see mass spectrum of the diepoxide in Figure S3B).
Linolenic acids ( $\alpha$ - and $\mathrm{y}^{-}$) were also transformed by MroUPO and CgNUPO (Figure S9). Both, monoepoxides (located in two different double bonds) and diepoxides were generated from alinolenic acid under the conditions tested. However, only one epoxide was observed in the $y$-linolenic acid reactions.

To compare the efficiency of MroUPO and CglUPO oxidizing unsaturated FA, apparent kinetic constants were determined for oleic acid oxidation (Table 3 ) in spite of the difficulties for GC- MS estimation of initial reaction rates. Regarding the turnover rate, Cg/UPO presented three-fold higher $k_{\text {cat }}$ values than MroUPO. In addition, the $K_{\mathrm{m}}$ value was four-fold higher for MroUPO, which represented less affinity by this enzyme compared to Cg/UPO. As a result, one order of magnitude higher catalytic efficiency $\left(k_{\text {cat }} / K_{\mathrm{m}}\right)$ was observed with CgNPO. In agreement with these results, Cg/UPO presented total turnover numbers (TTN) up to 8000 in oleic acid reactions when the substrate concentration was increased to $1 \mathrm{mM}$ (in 20\% acetone) while this number was half for MroUPO with $50 \mathrm{~nm}$ enzyme being used in both cases. This is a promising value accompanied by a significantly higher product amount (of about $0.5 \mathrm{mM}$ ) considering the limited solubility and other difficulties for fatty acid epoxidation. Likewise, the turnover frequency (TOF) was double for Cg/UPO $\left(2.2 \mathrm{~s}^{-1}\right)$ than for MroUPO $\left(1.1 \mathrm{~s}^{-1}\right)$. Solubility limitations prevented calculation of accurate kinetic constants for linoleic acid oxidation, since saturation could not be estimated especially for MroUPO (Figure S10), but higher activity than found for oleic acid was observed at high linoleic acid concentration.

FAME, usually obtained from vegetable oils by transesterification with methanol, were also tested as substrates of MroUPO and CgNPO. Namely, the methyl esters of two monounsaturated (myristoleic and oleic acids) and one diunsaturated FA (linoleic acid) were selected. Both peroxygenases were able to transform and epoxidize the monounsaturated FAME (Figures 3A,C). Cg/UPO showed similar selectivity towards the esters than with the free FA, but differences in the case of oleic acid were observed with MroUPO (Table 1). Regarding the methyl ester of linoleic acid, Cg/UPO showed a strict selectivity towards epoxidation (generating the diepoxide) while MroUPO was less selective towards diepoxide formation (Table 2, Figures 3B,D). In contrast, P450 BM3, which hydroxylate/epoxidize free fatty acids, was reported as unable to hydroxylate FAME ${ }^{[20]}$. This seems related to the fact that the free carboxyl group is required to fix the substrate at the entrance of P450 active site ${ }^{[6]}$. Finally, it is interesting that different patterns of oxygenation were observed with the cis isomers of the substrates (compared to the trans isomers). While MroUPO converted predominantly myristelaidic, palmitelaidic and elaidic acids (or their methyl esters) into the hydroxyderivatives at the allylic positions, Cg/UPO generated mainly the epoxides, with the only exception of elaidic acid (data not shown).

Table 3. Estimated kinetic parameters for oleic acid oxidation by CgIUPO and MroUPO. Data represent mean values of three replicates with standard errors

\begin{tabular}{lrrr}
\hline & $k_{\text {cat }}\left(\mathrm{s}^{-1}\right)$ & $K_{\mathrm{m}}(\mu \mathrm{M})$ & $k_{\text {cat }} / K_{\mathrm{m}}\left(\mathrm{M}^{-1} \cdot \mathrm{s}^{-1}\right)$ \\
\hline CgNUPO & $8.1 \pm 0.9$ & $10.7 \pm 4.0$ & $7.6 \pm 3.0 \times 10^{5}$ \\
MroUPO & $2.6 \pm 0.2$ & $38.9 \pm 6.1$ & $6.7 \pm 1.1 \times 10^{4}$ \\
\hline
\end{tabular}



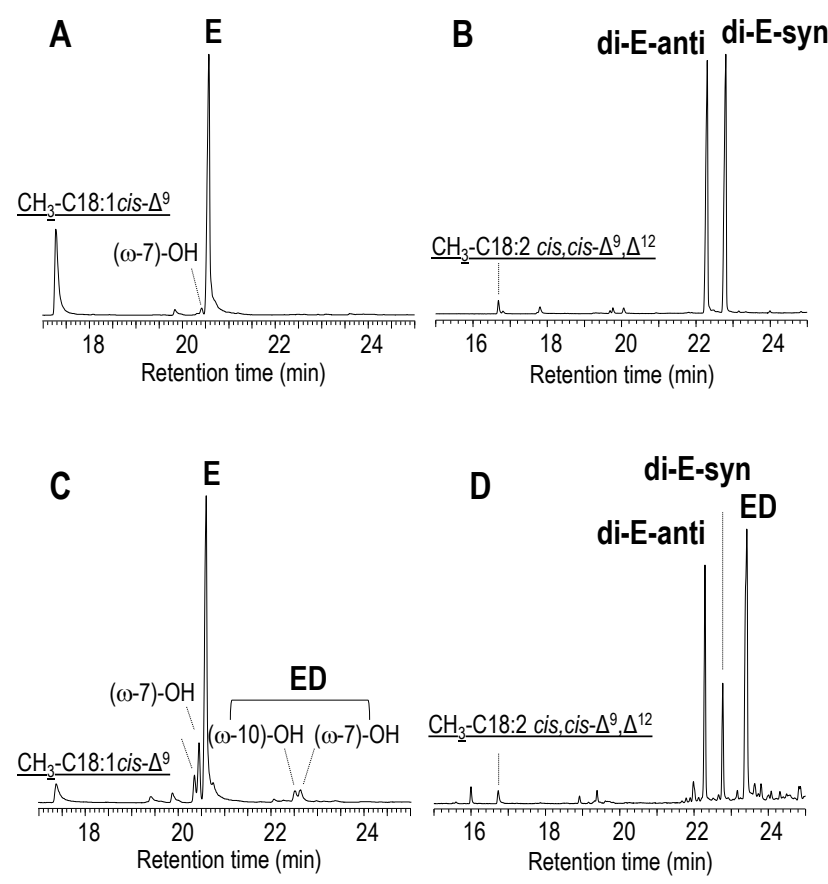

Figure 3. GC-MS of reactions of methyl oleate (left, underlined) with $1 \mu \mathrm{M}$ Cg/UPO at $60 \mathrm{~min}$ (A) and $200 \mathrm{nM}$ MroUPO at $120 \mathrm{~min}$ and (C), showing the epoxide (E), epoxide derivatives (ED); and the hydroxylated derivatives, and methyl linoleate (right, underlined) with $1 \mu \mathrm{M} C$ gNuPO at $60 \mathrm{~min}(\mathrm{~B})$ and $1 \mu \mathrm{M}$ MroUPO at $120 \mathrm{~min}$ (D), showing the diepoxides (di-E), epoxide derivatives (ED) and the hydroxylated derivatives of methyl linoleate.

The selective epoxidation of FA and FAME, a reaction of great interest for the chemical industry, ${ }^{[21]}$ must be added to the repertoire of UPOs, as dream biocatalysts for oxyfunctionalization chemistry. ${ }^{[9 ; 22 ; 23]}$ The structural determinants driving to selective epoxidations in MroUPO and CgNUPO (compared to AaeUPO and CciUPO) are difficult to be identified with the information available on these new heme-thiolate enzymes (note that only one UPO crystal structure has been published to date). However, in related $\mathrm{P} 450$, epoxidation vs hydroxylation rates have been related to the balance between the iron hydroperoxo and oxenoid forms after the oxidative activation of the enzyme, with an active site threonine being involve in the transition as the proton donor. ${ }^{[24 ; 25]}$ Interestingly, a threonine residue is present at the active sites of both AaeUPO and CcIUPO, and absent from those of MroUPO and $C g$ IUPO, as shown by Aranda et al. ${ }^{[26]}$ but its relevance in the FA hydroxylation/epoxidation balance is still to be experimentally investigated. This and other structural-functional studies with UPOs will help to understand the reaction mechanisms of these versatile enzymes, and to obtain ad-hoc variants for biotechnological application.

\section{Acknowledgements}

This work was funded by the BIORENZYMERY (AGL201453730-R) project of the Spanish MINECO (co-financed by FEDER) and by the CSIC 201740E071 project. H. Lund (Novozymes) is acknowledged for rCciUPO.
Keywords: epoxidation • fatty acids • fatty acid methyl esters fungal peroxygenases $\cdot$ oxidoreductases

[1] U. Biermann, U. Bornscheuer, M. A. R. Meier, J. O. Metzger, H. J. Schäfer, Angew. Chem. Int. Ed. 2011, 50, 3854-3871.

[2] N. Prileschajew, Ber. Dtsch. Chem. Ges. 1909, 42, 4811-4815.

[3] S. M. Danov, O. A. Kazantsev, A. L. Esipovich, A. S. Belousov, A. E. Rogozhin, E. A. Kanakov, Catal. Sci. Technol. 2017, 7, 36593675 .

[4] F. Björkling, H. Frykman, S. E. Godtfredsen, O. Kirk, Tetrahedron 1992, 48, 4587-4592.

[5] C. Tiran, J. Lecomte, E. Dubreucq, P. Villeneuve, OCL 2008, 15, 179-183.

[6] R. T. Ruettinger, A. J. Fulco, J. Biol. Chem. 1981, 256, 5728-5734

[7] G. Gröbe, M. Ullich, M. Pecyna, D. Kapturska, S. Friedrich, M. Hofrichter, K. Scheibner, AMB Express 2011, 1, 31-42.

[8] J. Kiebist, K. U. Schmidtke, J. Zimmermann, H. Kellner, N. Jehmlich, R. Ullrich, D. Zänder, M. Hofrichter, K. Scheibner, ChemBioChem 2017, 18, 563-569.

[9] M. Hofrichter, H. Kellner, M. J. Pecyna, R. Ullrich, Adv. Exp. Med. Biol. 2015, 851, 341-368.

[10] M. Hofrichter, R. Ullrich, M. J. Pecyna, C. Liers, T. Lundell, Appl. Microbiol. Biotechnol. 2010, 87, 871-897.

[11] A. Gutiérrez, E. D. Babot, R. Ullrich, M. Hofrichter, A. T. Martínez, J. C. del Río, Arch. Biochem. Biophys. 2011, 514, 33-43.

[12] R. Ullrich, J. Nuske, K. Scheibner, J. Spantzel, M. Hofrichter, Appl. Environ. Microbiol. 2004, 70, 4575-4581.

[13] M. J. Pecyna, R. Ullrich, B. Bittner, A. Clemens, K. Scheibner, R. Schubert, M. Hofrichter, Appl. Microbiol. Biotechnol. 2009, 84, 885 897.

[14] D. Floudas, M. Binder, R. Riley, K. Barry, R. A. Blanchette, B. Henrissat, A. T. Martínez, R. Otillar, J. W. Spatafora, J. S. Yadav et al., Science 2012, 336, 1715-1719.

[15] J. E. Stajich, S. K. Wilke, D. Ahren, C. H. Au, B. W. Birren, M. Borodovsky, C. Burns, B. Canbäck, L. A. Casselton, C. K. Cheng et al., Proc. Natl. Acad. Sci. USA 2010, 107, 11889-11894.

[16] E. D. Babot, J. C. del Río, L. Kalum, A. T. Martínez, A. Gutiérrez, Biotechnol. Bioeng. 2013, 110, 2332

[17] E. D. Babot, J. C. del Río, M. Cañellas, F. Sancho, F. Lucas, V. Guallar, L. Kalum, H. Lund, G. Gröbe, K. Scheibner, R. Ullrich, M. Hofrichter, A. T. Martínez, A. Gutiérrez, Appl. Environ. Microbiol. 2015, 81, 4130-4142.

[18] A. Olmedo, C. Aranda, J. C. del Río, J. Kiebist, K. Scheibner, A. T. Martínez, A. Gutiérrez, Angew. Chem. Int. Ed. 2016, 55, 1224812251.

[19] A. Olmedo, J. C. del Río, J. Kiebist, K. Scheibner, A. T. Martínez, A. Gutiérrez, Chem. -Eur. J. 2017, 23, 16985-16989.

[20] Y. Miura, A. J. Fulco, Biochim. Biophys. Acta-Lipids Lipid Metab. $1975,388,305-317$

[21] A. Corma, S. Iborra, A. Velty, Chem. Rev. 2007, 107, 2411-2502.

[22] Y. Wang, D. Lan, R. Durrani, F. Hollmann, Curr. Opin. Chem. Biol. 2017, 37, 1-9.

[23] S. Bormann, A. G. Baraibar, Y. Ni, D. Holtmann, F. Hollmann, Catal. Sci. Technol. 2015, 5, 2038-2052.

[24] A. D. N. Vaz, D. F. McGinnity, M. J. Coon, Proc. Natl. Acad. Sci. USA 1998, 95, 3555-3560.

[25] E. G. Hrycay, S. M. Bandiera, Adv. Exp. Med. Biol. 2015, 851, 161

[26] C. Aranda, R. Ullrich, J. Kiebist, K. Scheibner, J. C. del Río, M. Hofrichter, A. T. Martínez, A. Gutiérrez, Catal. Sci. Technol. 2018, 8, 2394-2401. 
Entry for the Table of Contents (Please choose one layout)

Layout 1:

COMMUNICATION

Layout 2:

\section{COMMUNICATION}

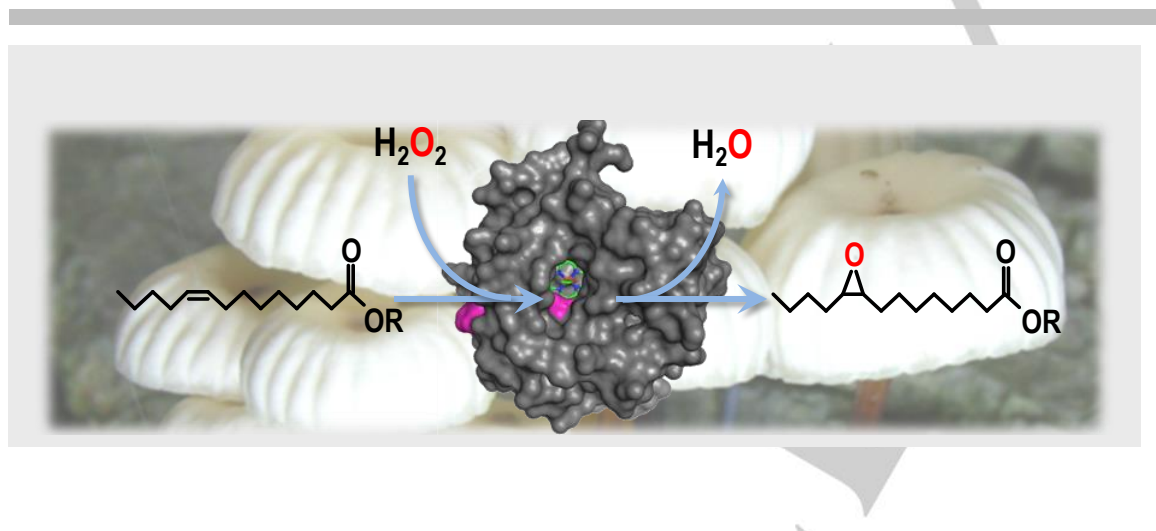

Carmen Aranda ${ }^{\ddagger}$, Andrés Olmedo ${ }^{\ddagger}$, Jan Kiebist, Katrin Scheibner, José C. del Río, Angel T. Martínez, and Ana Gutiérrez*

Page No. - Page No.

Selective Epoxidation of Fatty Acids and Fatty Acid Methyl Esters by Fungal Peroxygenases

Recently discovered fungal unspecific peroxygenases from Marasmius rotula and Chaetomium globosum catalyze the epoxidation of unsaturated fatty acids (FA) and FA methyl esters (FAME), unlike the well-known peroxygenases from Agrocybe aegerita and Coprinopsis cinerea. Reactions of a series of unsaturated FA and FAME revealed high substrate conversion (with up to 8000 total turnover number in oleic acid reactions) and selectivity towards epoxidation (often $>90 \%$ ), the best results being obtained with the $C$. globosum enzyme. 


\section{Table of contents}

1. Supplemental materials and methods

1.1 Enzymes

1.2 Model substrates

1.3 Enzymatic reactions

1.4 Enzyme kinetics

1.4 GC-MS analyses

2. Supplemental figures

3. Supplemental references

4. Complete reference cited in the main text

\section{Supplemental materials and methods}

\subsection{Enzymes}

MroUPO is a wild enzyme isolated from cultures of $M$. rotula DSM 25031, a fungus deposited at the German Collection of Microorganisms and Cell Cultures (Braunschweig, Germany). It was purified by fast protein liquid chromatography (FPLC) to apparent homogeneity, confirmed by sodium dodecylsulfate-polyacrylamide gel electrophoresis under denaturing conditions, and showed a molecular mass of $32 \mathrm{kDa}$ and isoelectric point of $\mathrm{pH}$ 5.0-5.3. The UV-visible spectrum of the enzyme showed a characteristic maximum at $418 \mathrm{~nm}$ (Soret band of heme-thiolate proteins). ${ }^{[1]}$

$C g l \mathrm{UPO}(36 \mathrm{kDa})$ is a wild enzyme isolated from cultures of $C$. globosum DSM 62110, from the German Collection of Microorganisms and Cell cultures. It was purified by ammonium sulfate precipitation and successive FPLC on Q-Sepharose FF, Superdex 75, and Mono Q columns using an ÄKTA FPLC system (GE Healthcare). ${ }^{[2]}$

rCciUPO (used with comparative purpose) was provided by Novozymes A/S (Bagsvaerd, Denmark). This recombinant enzyme corresponds to the protein model 7249 from the sequenced $C$. cinerea genome available at the JGI (http://genome.jgi.doe.gov/Copci1), expressed in Aspergillus oryzae (patent WO/2008/119780), and purified using a combination of S-Sepharose and SP-Sepharose ion-exchange chromatography. The recombinant peroxygenase preparation is an electrophoretically homogeneous glycoprotein with a molecular mass around $44 \mathrm{kDa}$, a typical UV-vis spectrum, and the ability to oxygenate different aromatic compounds with a specific activity of approximately $100 \mathrm{U} \cdot \mathrm{mg}^{-1}$ (measured as described below). SDS PAGE of different UPO preparations are shown in Fig. S1.

One UPO activity unit is defined as the amount of enzyme oxidizing $1 \mu \mathrm{mol}$ of veratryl alcohol to veratraldehyde $\left(\varepsilon_{310} 9300 \mathrm{M}^{-1} \cdot \mathrm{cm}^{-1}\right)$ in $1 \mathrm{~min}$ at $24^{\circ} \mathrm{C}, \mathrm{pH} 7$, after addition of $2.5 \mathrm{mM} \mathrm{H}_{2} \mathrm{O}_{2}$. Enzyme concentration was estimated from the characteristic spectrum of peroxidase complex with carbon monoxide ${ }^{[3]}$.

\subsection{Model substrates}

A series of unsaturated lipids (cis isomers) from Sigma-Aldrich was used including: i) fatty acids such as myristoleic (cis-9-tetradecenoic), palmitoleic (cis-9-hexadecenoic), oleic (cis-9-octadecenoic), linoleic (cis,cis-9,12-octadecadienoic), $\alpha-$ (cis, cis, cis9,12,15), and $\gamma$-(cis, cis, cis-6, 9,12) linolenic (octadecatrienoic) acids, gondoic (cis-11eicosenoic) and erucic (cis-13-docosenoic) acids; and vi) fatty acid esters such as methyl myristoleate, methyl oleate and methyl linoleate. The trans isomers such as myristelaidic 
(trans-9-tetradecenoic), palmitelaidic (trans-9-hexadecenoic) and elaidic (trans-9octadecenoic) acids were also obtained from Sigma-Aldrich. The following standards of epoxides were also used, rac cis-9,10-epoxyoctadecanoic acid and $( \pm)$ 9(10)-EpOME (9,10-cis-epoxide of linoleic acid) from Santa Cruz Biotechnology; ( \pm ) 12(13)-EpOME (12,13-cis-epoxide of linoleic acid) from Cayman; and 9,10-12,13-diepoxyoctadecanoic acid from Larodan.

\subsection{Enzymatic reactions}

Reactions of the model compounds at $0.1 \mathrm{mM}$ concentration were performed with: i) MroUPO (100-400 nM) in $50 \mathrm{mM}$ sodium phosphate $\left(\mathrm{pH} \mathrm{5.5)}\right.$ at $30^{\circ} \mathrm{C}$ or $40^{\circ} \mathrm{C}$ and $30-$ 120 min reaction time, in the presence of $0.5-5 \mathrm{mM} \mathrm{H}_{2} \mathrm{O}_{2}$ and ii) $C g l \mathrm{UPO}(30-1000 \mathrm{nM})$ in $50 \mathrm{mM}$ sodium phosphate $(\mathrm{pH} 7)$ at $30^{\circ} \mathrm{C}$ or $40^{\circ} \mathrm{C}$ and $30-60$ min reaction time, in the presence of 0.5-5 $\mathrm{mM} \mathrm{H}_{2} \mathrm{O}_{2}$. In all cases the $\mathrm{H}_{2} \mathrm{O}_{2}$ was added in pulses. Prior to use, the substrates were dissolved in acetone and added to the buffer to give a final acetone concentration of $20 \%(\mathrm{v} / \mathrm{v})$ although concentrations of $40 \%$ were also tested with some compounds. In control experiments, substrates were treated under the same conditions (including 2.5-5 $\mathrm{mM} \mathrm{H}_{2} \mathrm{O}_{2}$ ) but without enzyme. Products were recovered by liquid-liquid extraction with methyl tert-butyl ether and dried under $\mathrm{N}_{2}$. N,OBis(trimethylsilyl)trifluoroacetamide (Supelco) was used to prepare trimethylsilyl (TMS) derivatives that were analyzed by GC-MS.

\subsection{Enzyme kinetics}

To study the kinetics of fatty acids (oleic and linoleic acid) oxidation, reactions in $1 \mathrm{~mL}$ vials with $50 \mathrm{nM}$ of enzyme (MroUPO and $C g l \mathrm{UPO}$ ) were carried out. Substrate concentration was varied between $6.25 \mu \mathrm{M}$ and $400 \mu \mathrm{M}$ and $20 \%(\mathrm{v} / \mathrm{v})$ of acetone was used as cosolvent. The reactions were initiated with $0.5 \mathrm{mM} \mathrm{H}_{2} \mathrm{O}_{2}$ and stopped after $1 \mathrm{~min}$ ( $C g l \mathrm{UPO}$ ) or $5 \mathrm{~min}$ (MroUPO) with $100 \mu \mathrm{L}$ of $100 \mathrm{mM}$ sodium azide solution by vigorous shaking. All reactions were carried out in triplicate. Products quantification was performed by GC-MS (as described below) using external standard curves and response factors of authentic standards. Kinetic parameters $\left(k_{\mathrm{cat}}, K_{\mathrm{m}}\right)$ were obtained by fitting the data to the Michaelis-Menten equation using SigmaPlot software (Systat Softwarwe Inc., San Jose, CA, USA). For TTN (total turnover number) determination, substrate concentration was increased to $1 \mathrm{mM}$ and $5 \mathrm{mM}$ using methyl- $\beta$-cyclodextrin (from Sigma-Aldrich) in a final reaction concentration of $5 \mathrm{mM}$ or $20 \%(\mathrm{v} / \mathrm{v})$ of acetone using $50 \mathrm{nM}$ of both enzymes. The highest product concentration was attained using acetone in the case of $C g / \mathrm{UPO}$ ( $1 \mathrm{mM}$ substrate, $400 \mu \mathrm{M}$ products) and methyl- $\beta$-cyclodextrin in the case of MroUPO (1mM substrate, $200 \mu \mathrm{M}$ products).

\subsection{GC-MS analyses}

The analyses were performed with a Shimadzu GC-MS QP2010 Ultra, using a fusedsilica DB-5HT capillary column $(30 \mathrm{~m} \times 0.25 \mathrm{~mm}$ internal diameter, $0.1 \mu \mathrm{m}$ film thickness) from $\mathrm{J} \& \mathrm{~W}$ Scientific. The oven was heated from $120^{\circ} \mathrm{C}(1 \mathrm{~min})$ to $300^{\circ} \mathrm{C}(15$ $\min )$ at $5^{\circ} \mathrm{C} \cdot \mathrm{min}^{-1}$. The injection was performed at $300^{\circ} \mathrm{C}$ and the transfer line was kept at $300^{\circ} \mathrm{C}$. Compounds were identified by mass fragmentography, and comparing their mass spectra with those of the Wiley and NIST libraries and standards. Quantification was obtained from total-ion peak area, using molar response factors of the same or similar 
compounds. Data from replicates were averaged and, in all the standard deviations were below $5 \%$ of the mean values. 


\section{Supplemental figures}

A

B

C

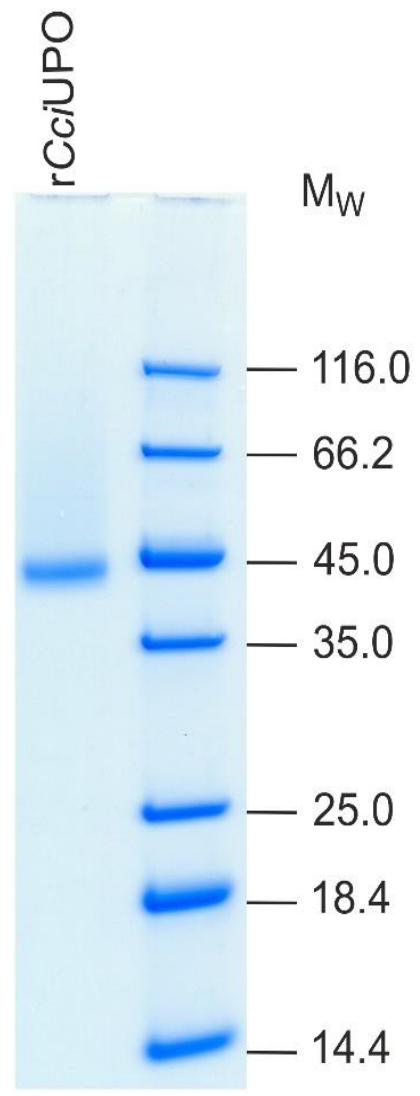

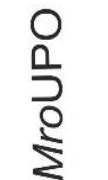

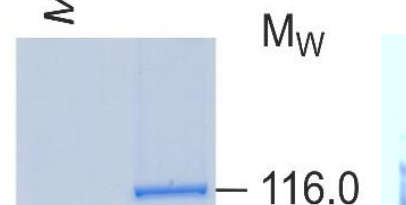

م)

$\mathrm{M}_{\mathrm{W}}$

$-130$

$-100$

$-70$

$-66.2$

$-45.0$

$-55$

$-40$

$-35.0$

$-35$

$-25$

$-25.0$

$-15$

$-18.4$

$-14.4$

Figure S1. SDS PAGE of different UPO preparations: rCciUPO (A), MroUPO (B) and CglUPO (C). 10-12\% Bis-Tris was used, and the proteins were visualized with a colloidal Blue staining (Invitrogen). Conditions $(50 \mathrm{mM}$ dithiothreitol) resulted in monomeric MroUPO. Low molecular weight standards (Thermo Scientific, Darmstadt, Germany) were included. 

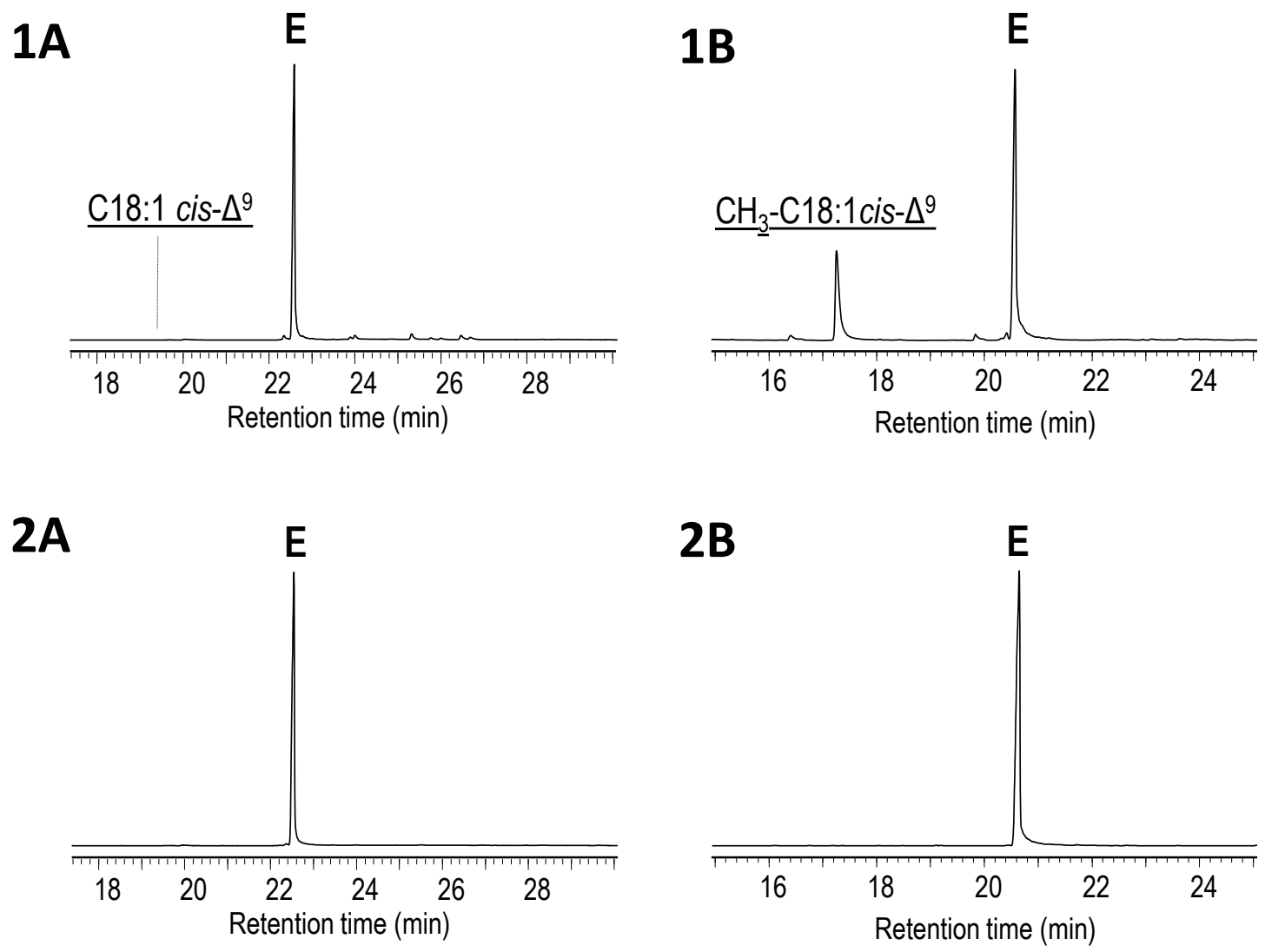

Figure S2. GC-MS chromatograms of cis-9,10-epoxistearic acid (E) from oleic acid (underlined) reaction with $C g l \mathrm{UPO}(\mathbf{1 A})$ and $c i s-9,10$-epoxistearic acid standard $(\mathbf{2 A})$; and of cis-9,10-epoxistearic acid methyl ester (E) from oleic acid methyl ester (underlined) reaction with $C g l$ UPO (1B) $c i s-9,10$-epoxistearic acid methyl ester standard (2B). 

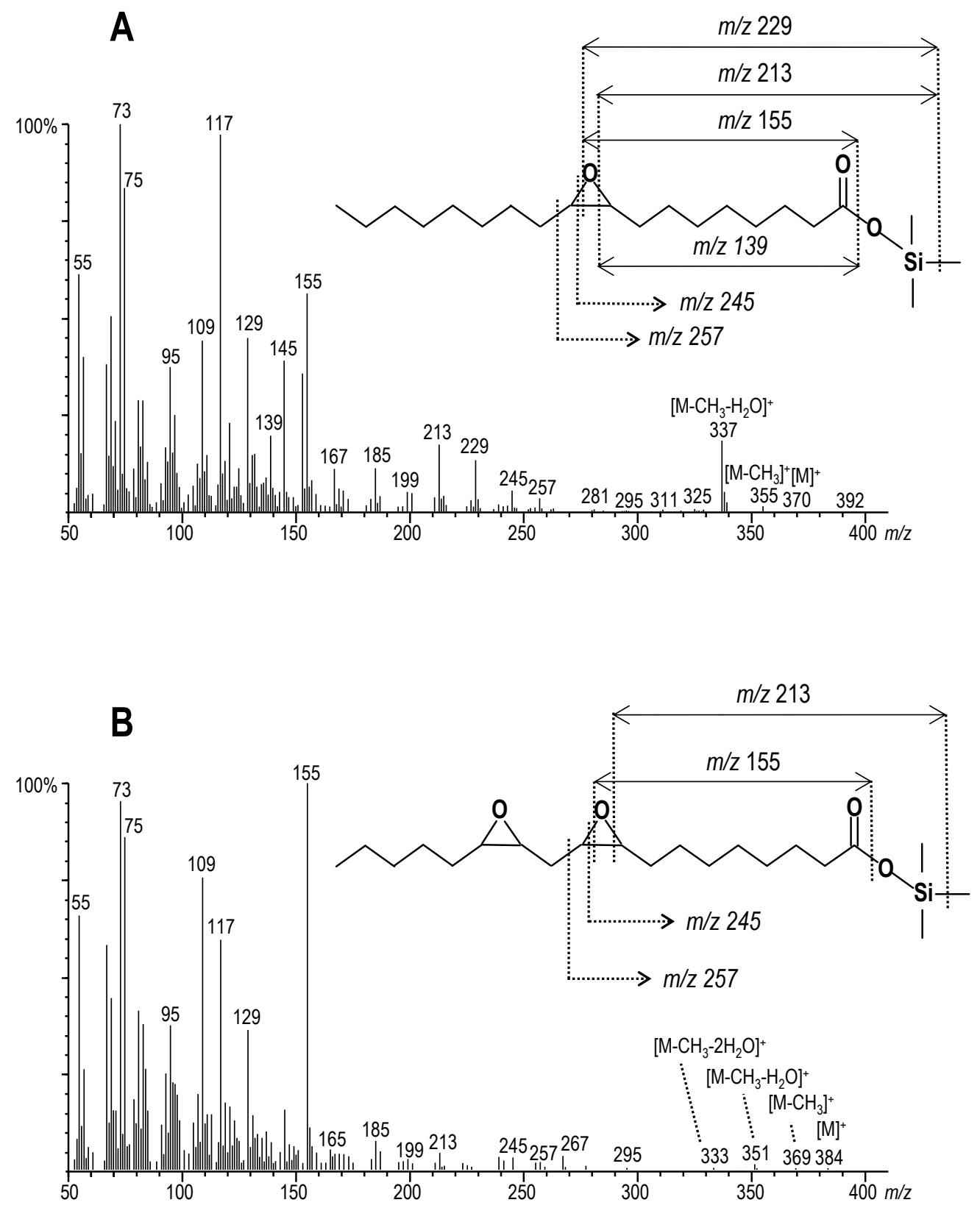

Figure S3. Mass spectra and formula/fragmentation of oleic acid epoxide (A) and linoleic acid diepoxide (B) (as trimethylsilyl derivatives) from $C g l$ UPO and MroUPO reactions with oleic acid and linoleic acid, respectively. 

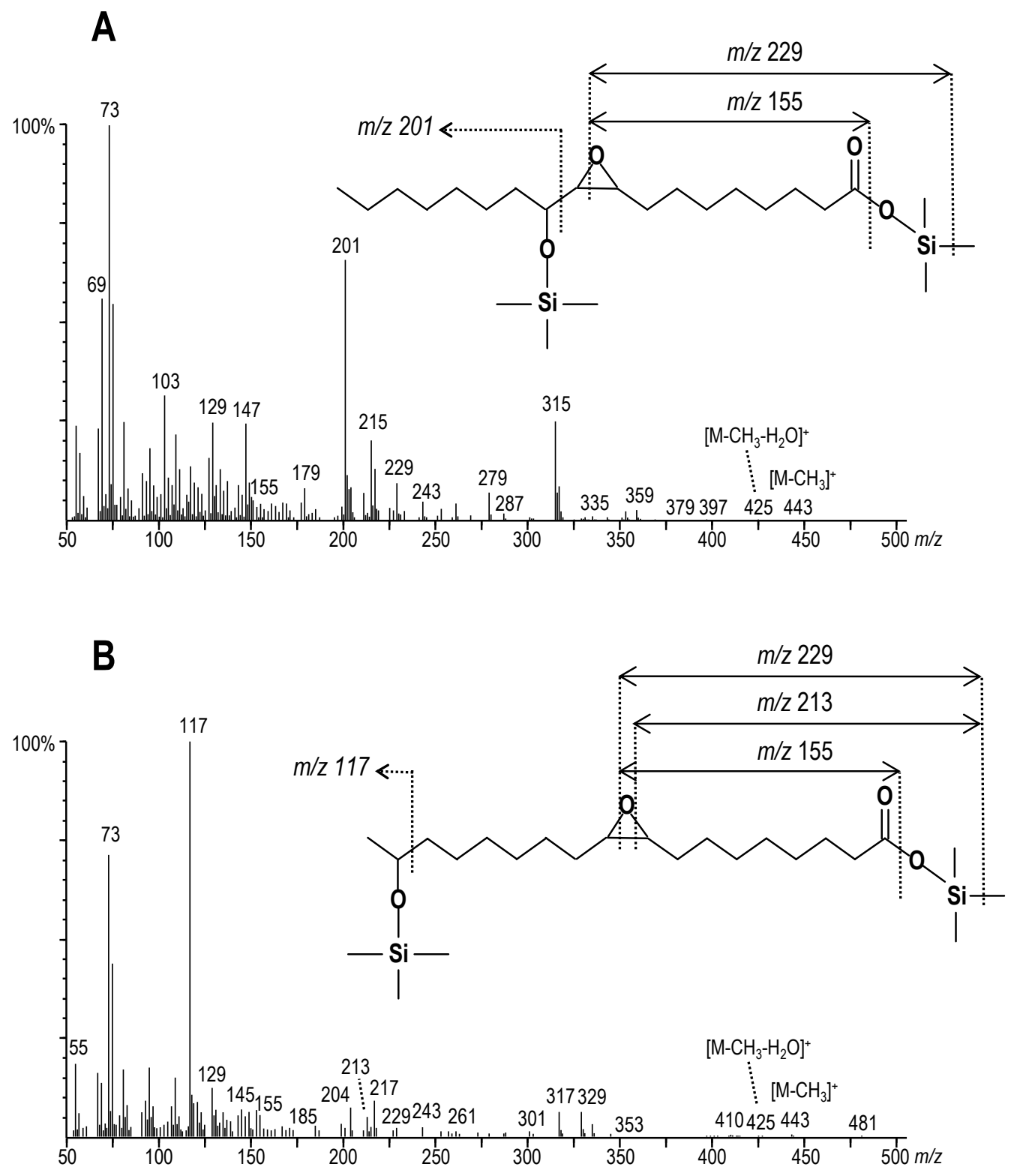

Figure S4. Mass spectra and formula/fragmentation of compounds tentatively assigned as hydroxylated derivative at $(\omega-7)$ position $(\mathbf{A})$ and at $(\omega-1)$ position $(\mathbf{B})$ of oleic acid epoxide (as trimethylsilyl derivatives) from MroUPO reactions with oleic acid (Fig. 1B). 


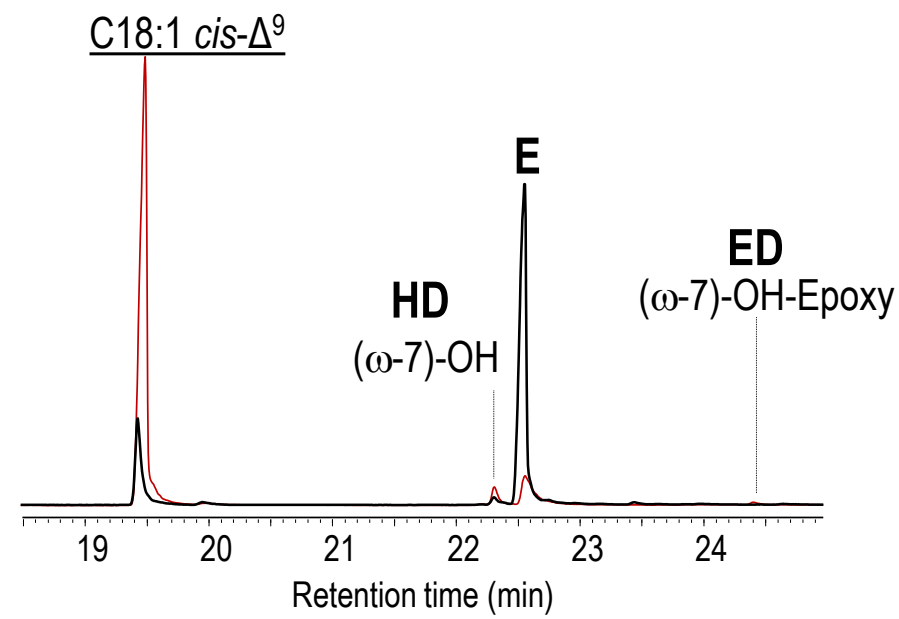

Figure S5. GC-MS of conversion of oleic acid (underlined) by the same dose (50 nM) of CglUPO (black) and MroUPO (red), within $5 \mathrm{~min}$, and $2.5 \mathrm{mM} \mathrm{H}_{2} \mathrm{O}_{2}$, showing the epoxide (E), epoxide derivatives (ED) and the hydroxylated derivatives (HD) of oleic acid at subterminal positions (see mass spectra of the epoxide in Figures S2). 


\section{Cg/UPO}
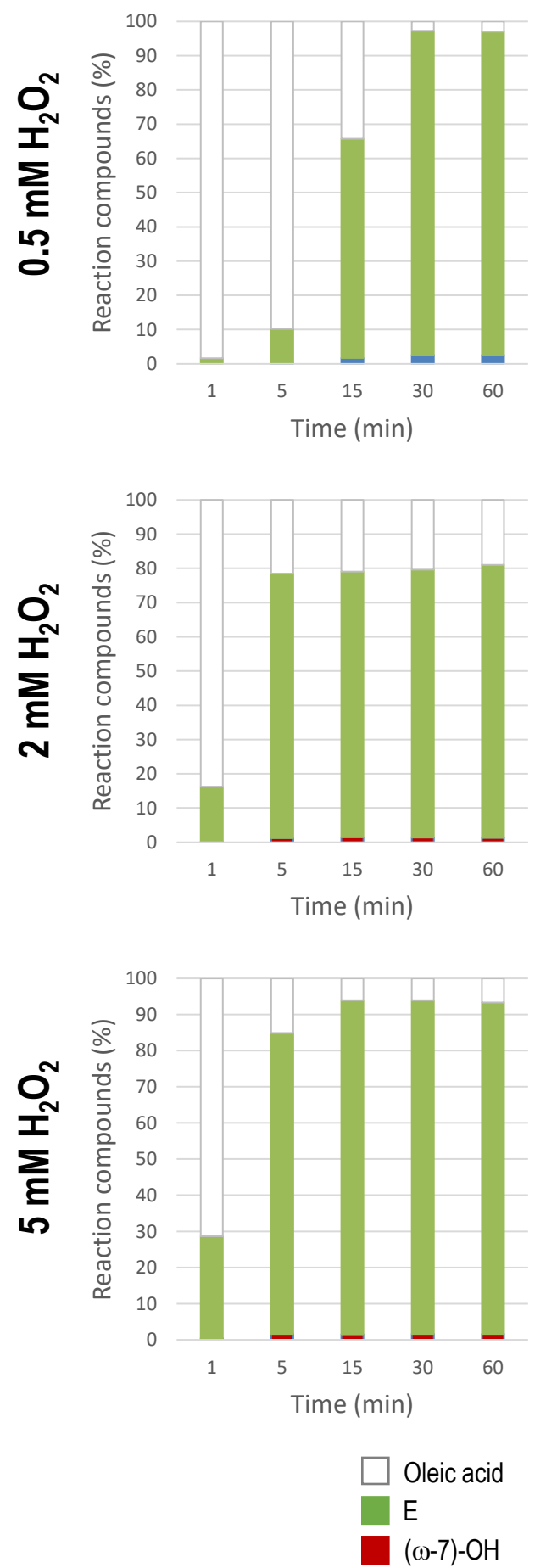

MroUPO
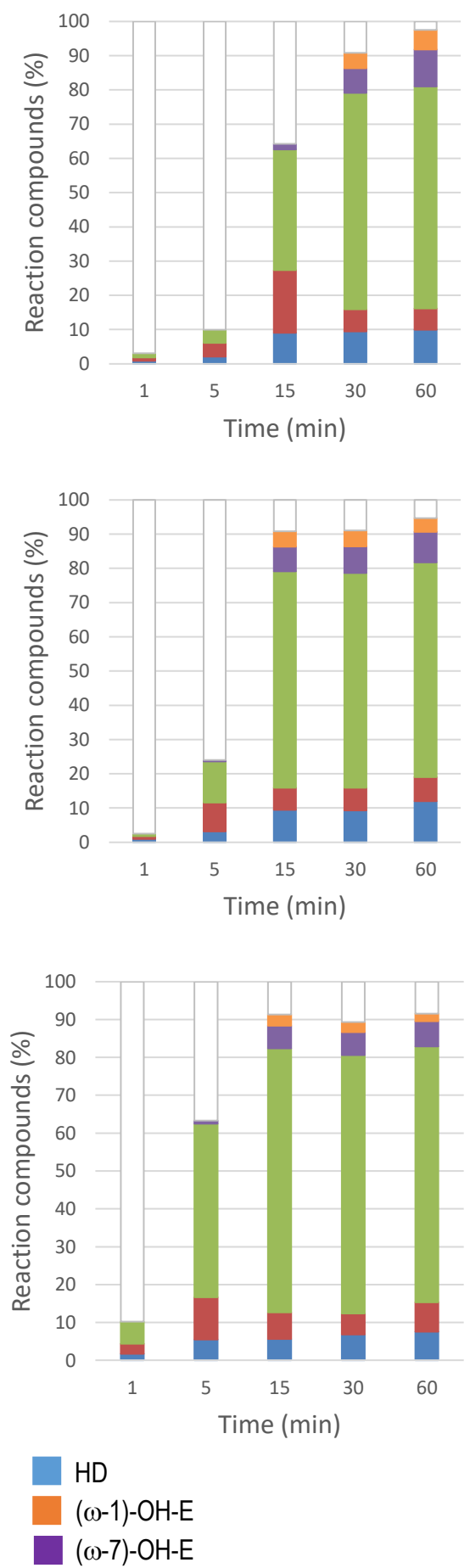

Figure S6. Molar percentage of compounds from reactions of oleic acid with $50 \mathrm{nM}$ CglUPO and $100 \mathrm{nM}$ MroUPO, under different $\mathrm{H}_{2} \mathrm{O}_{2}$ doses and reaction times, showing the remaining substrate, epoxide $(E)$, hydroxylated derivatives of the epoxide at $(\omega-1)$ and ( $\omega-7)$ positions and the hydroxylated derivatives (HD) of oleic acid at subterminal positions. 


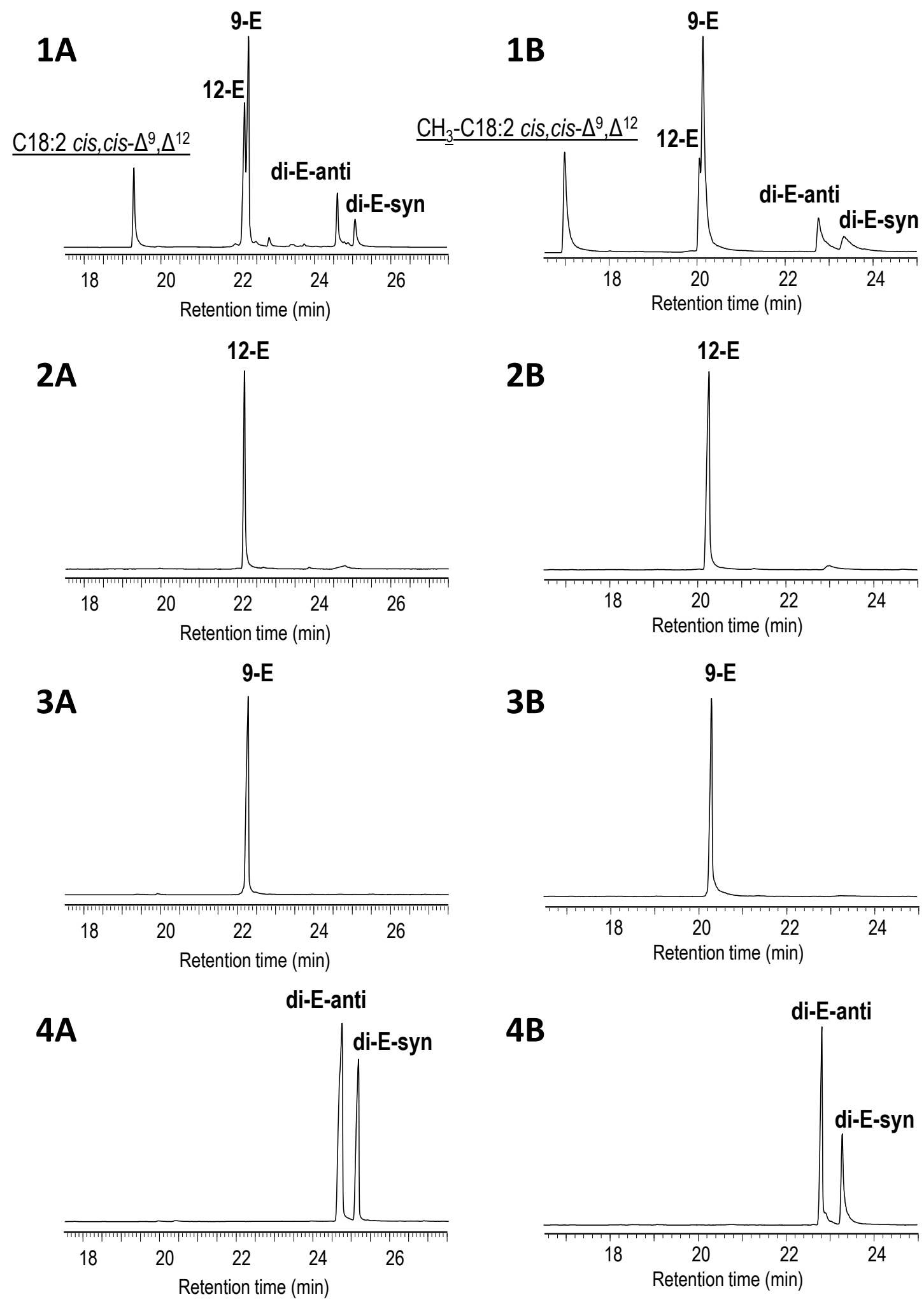

Figure S7. GC-MS chromatograms of 12,13-cis-epoxide of linoleic acid (12-E); 9,10cis-epoxide of linoleic acid (9-E) and 9,10-12,13-diepoxyoctadecanoic acid (di-E-anti and di-E-syn) from linoleic acid (underlined) reaction with $C g I \mathrm{UPO}(\mathbf{1 A})$ and of authentic standards cis-12,13-epoxistearic acid (2A); cis-9,10-epoxistearic acid (3A); and 9,1012,13-diepoxyoctadecanoic acid (4A) as well as their corresponding methyl esters (1B4B). 

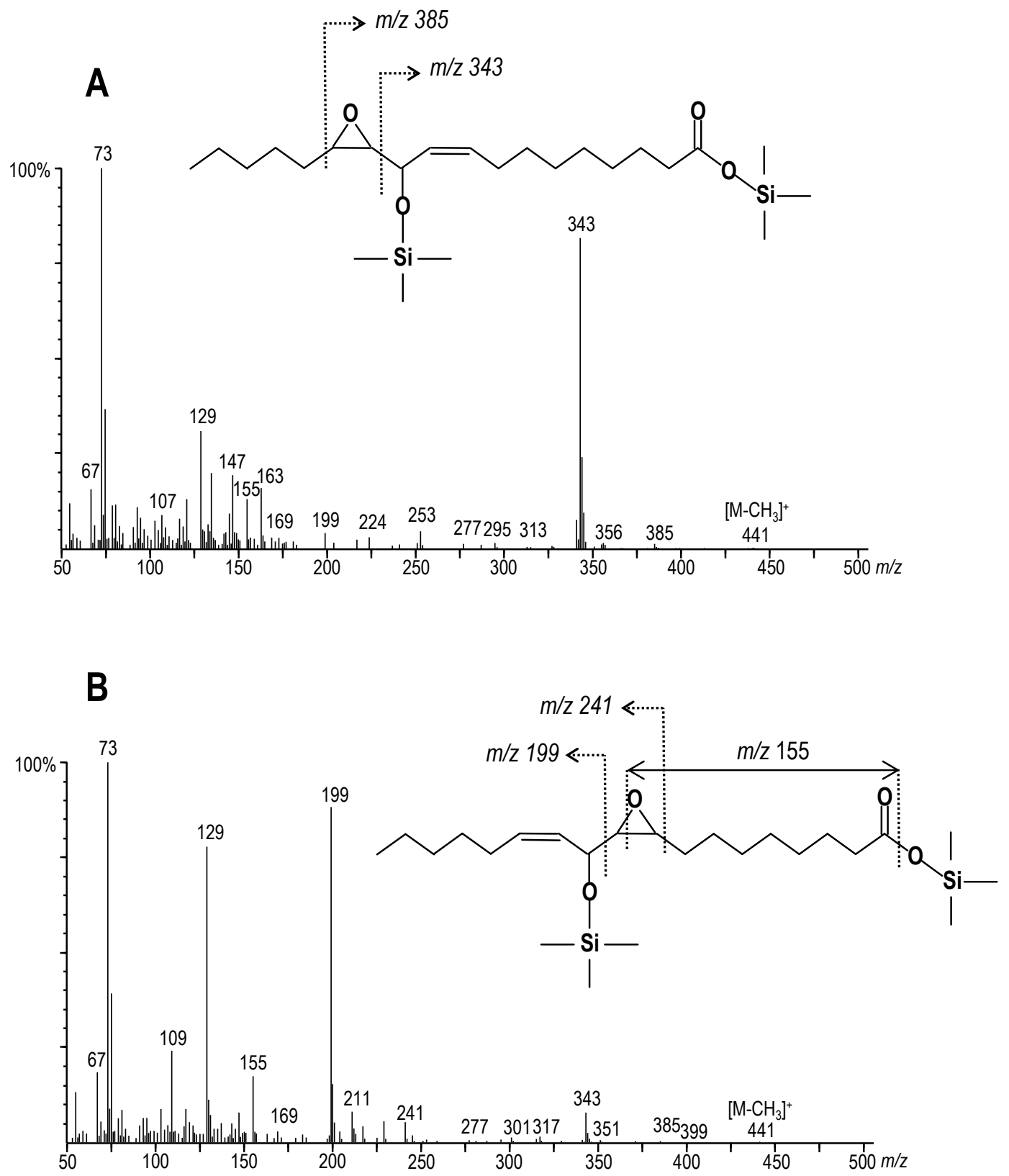

Figure S8. Mass spectra and formula/fragmentation of compounds tentatively assigned as hydroxylated derivatives at ( $\omega$-7) position of linoleic acid 12-epoxide (A) and 9epoxide (B) (as trimethylsilyl derivatives) from MroUPO reactions with linoleic acid (Fig. 2B). 

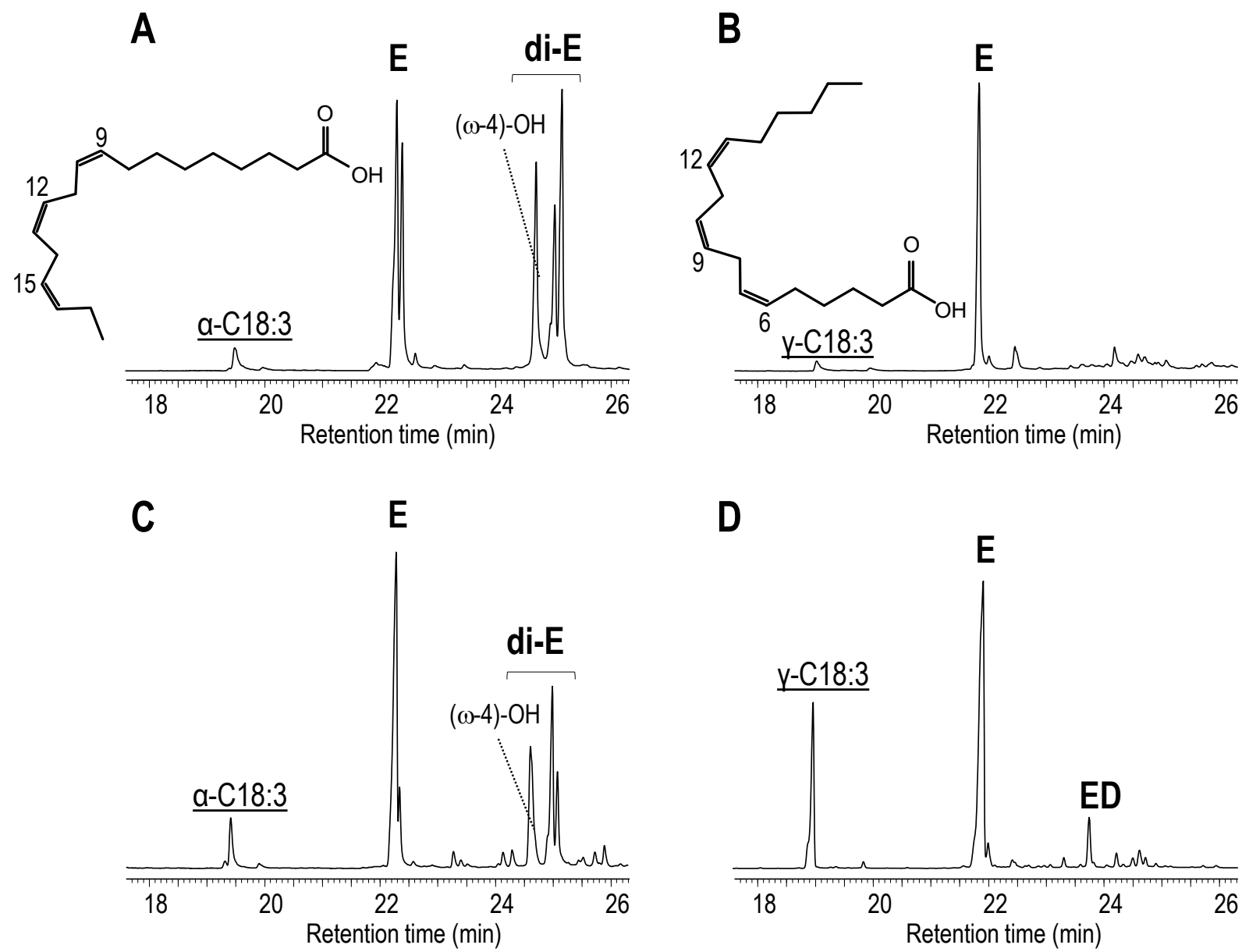

Figure S9. GC-MS of reactions of $\alpha$-linolenic acid (left) at 30 min with $63 \mathrm{nM} C g l \mathrm{UPO}$ (A) and $100 \mathrm{nM}$ MroUPO (C), and $\gamma$-linolenic acid (right) at $30 \mathrm{~min}$ with $100 \mathrm{nM}$ $C g l$ UPO (B) and $63 \mathrm{nM}$ MroUPO (D), showing the remaining substrates (underlined), monoepoxides (E), diepoxides (di-E) and hydroxylated derivatives. 
A

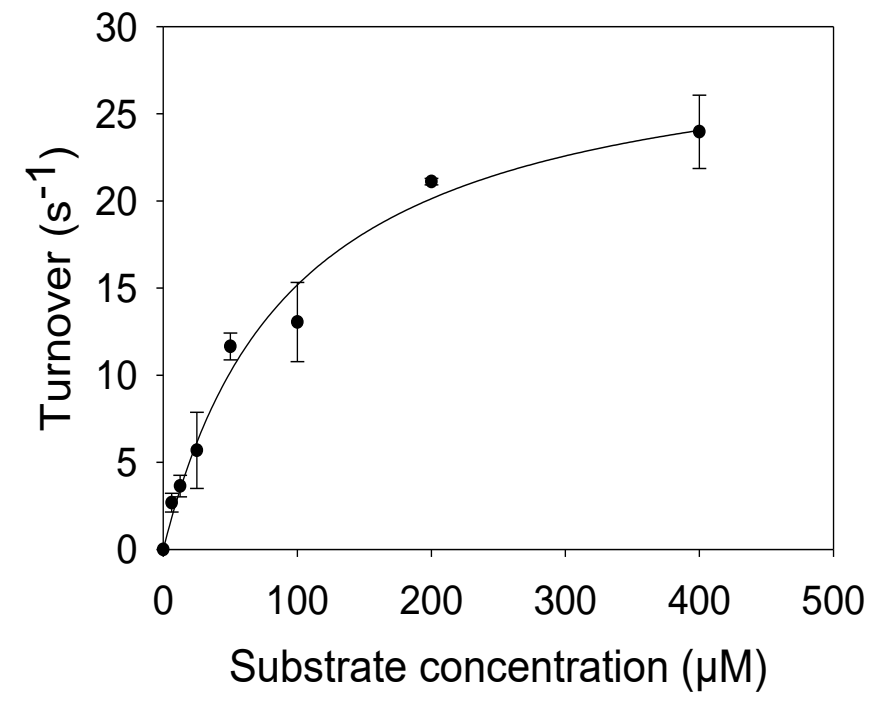

B

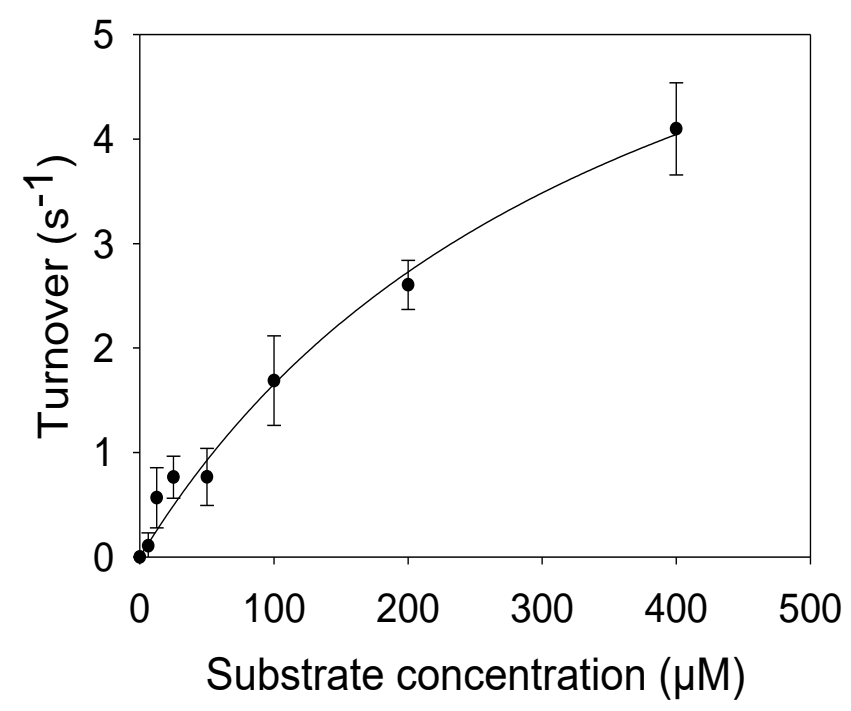

Figure S10. Kinetic studies for the enzymatic oxidation of linoleic acid by $\mathrm{Cg} l \mathrm{UPO}$ (A) and MroUPO (B). 


\section{Supplemental references}

[1] G. Gröbe, M. Ullrich, M. Pecyna, D. Kapturska, S. Friedrich, M. Hofrichter, K. Scheibner, AMB Express 2011, 1, 31-42.

[2] J. Kiebist, K. U. Schmidtke, J. Zimmermann, H. Kellner, N. Jehmlich, R. Ullrich, D. Zänder, M. Hofrichter, K. Scheibner, ChemBioChem 2017, 18, 563-569.

[3] C. R. Otey, Methods Mol. Biol. 2003, 230, 137-139.

\section{Complete reference cited in the main text}

[14] D. Floudas, M. Binder, R. Riley, K. Barry, R. A. Blanchette, B. Henrissat, A. T. Martínez, R. Otillar, J. W. Spatafora, J. S. Yadav, A. Aerts, I. Benoit, A. Boyd, A. Carlson, A. Copeland, P. M. Coutinho, R. P. de Vries, P. Ferreira, K. Findley, B. Foster, J. Gaskell, D. Glotzer, P. Górecki, J. Heitman, C. Hesse, C. Hori, K. Igarashi, J. A. Jurgens, N. Kallen, P. Kersten, A. Kohler, U. Kües, T. K. A. Kumar, A. Kuo, K. LaButti, L. F. Larrondo, E. Lindquist, A. Ling, V. Lombard, S. Lucas, T. Lundell, R. Martin, D. J. McLaughlin, I. Morgenstern, E. Morin, C. Murat, M. Nolan, R. A. Ohm, A. Patyshakuliyeva, A. Rokas, F. J. Ruiz-Dueñas, G. Sabat, A. Salamov, M. Samejima, J. Schmutz, J. C. Slot, F. St.John, J. Stenlid, H. Sun, S. Sun, K. Syed, A. Tsang, A. Wiebenga, D. Young, A. Pisabarro, D. C. Eastwood, F. Martin, D. Cullen, I. V. Grigoriev, D. S. Hibbett, Science 2012, 336, 1715-1719. 